\title{
One in Fifteen Family Physicians Principally Provide Emergency or Urgent Care
}

\author{
Stephen Petterson, PhD, Lars Peterson, MD, PhD, Robert L. Phillips, MD, MSPH, \\ Miranda Moore, PhD, Sean Finnegan, MS, Megan Coffman, MPH, and \\ Andrew Bazemore, MD, MPH
}

A small but nontrivial proportion of US family physicians devote most of their time providing emergency or urgent care. With considerable attention focused on expanding access to primary care, it is important to account for providers principally working outside of traditional primary care. (J Am Board Fam Med 2014;27:447-448.)

Keywords: Critical Care, Emergency Medicine, Health Policy, Primary Health Care, Rural Health

Family physicians adapt their care depending on the rurality, market conditions, and needs in their

This article was externally peer reviewed.

From the American Board of Family Medicine, Lexington, KY (LP, RLP), and The Robert Graham Center, Washington, DC (SP, MM, SF, MC, AB).

Funding: none.

Conflict of interest: none declared.

Corresponding author: Lars Peterson, MD, PhD, American Board of Family Medicine, 1648 McGrathiana Parkway, Suite 550, Lexington, KY 40511-1247 (E-mail: lpeterson@ theabfm.org).

\section{See Related Commentary on Page 444.}

community. Most family physicians provide comprehensive primary care associated with the profession's traditional "basket of services," ${ }^{1}$ but some adapt their work to meet needs in other important settings, including emergency departments and urgent care centers. ${ }^{2}$

We used data routinely collected from all family physicians during their Maintenance of Certification for Family Physicians examination application between 2008 and 2012 ( $\mathrm{n}=22,192)$; we restricted our analysis to those who passed the examination to avoid double-counting physicians. We used rural urban commuting area codes to classify rurality. ${ }^{3}$

We found that about 1 in 15 respondents $(6.7 \%)$ devoted $\geq 80 \%$ of their time to either emergency

Figure 1. Percentage of family physicians passing the Maintenance of Certification-Family Physician examination from 2008 to 2012 who report devoting at least $80 \%$ of their time to either emergency care or urgent care.

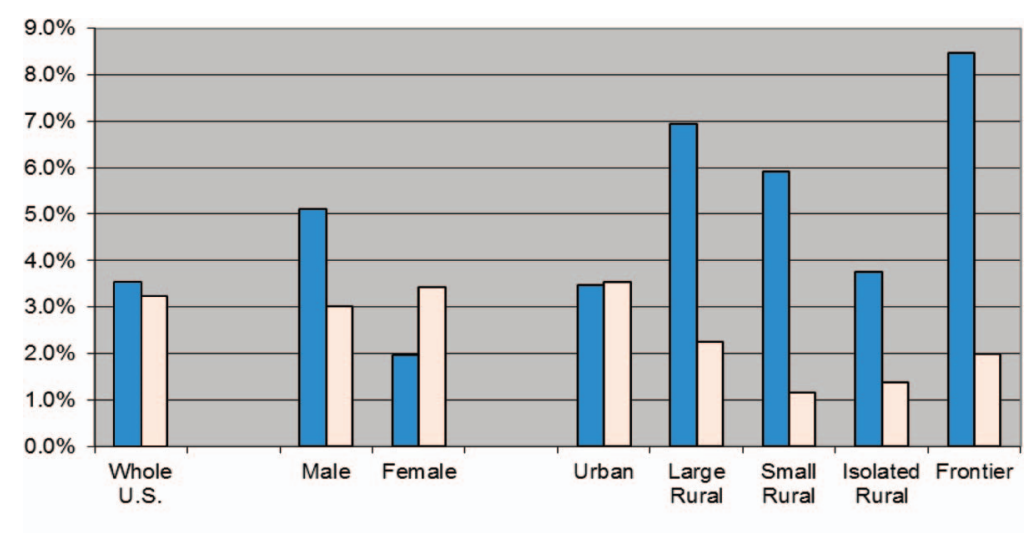

aEmergency Care $80 \%+$ aUrgent Care $80 \%+$ 
(3.6\%) or urgent care (3.1\%). As expected, increasing rurality was associated with greater proportions of family physicians working principally in emergency care. ${ }^{4}$ More male family physicians work in emergency care, whereas more female physicians work in urgent care.

With the growing national consensus regarding the need to maintain and expand the primary care pipeline, it is important that workforce planners and policymakers be able to accurately assess the availability of primary care. This ability relies on being able to identify primary care physicians serving in clinical roles other than primary care. A small but important percentage of family physicians are serving as emergency and urgent care physicians, particularly in rural areas.

\section{References}

1. Martin JC, Avant RF, Bowman MA, et al; Future of Family Medicine Project Leadership Committee. The Future of Family Medicine: a collaborative project of the family medicine community. Ann Fam Med 2004; 2(Suppl 1):S3-32.

2. Gerard WA, Staffer A, Bullock K, Pugno P. Family physicians in emergency medicine: new opportunities and critical challenges. Ann Fam Med 2010;8: 564-5.

3. WWAMI Rural Health Research Center. RUCA data. General methods. Available from: http://depts. washington.edu/uwruca/ruca-methodology.php. Accessed November 21, 2013.

4. Peterson LE, Dodoo M, Bennett KJ, Bazemore A, Phillips RL Jr. Nonemergency medicine-trained physician coverage in rural emergency departments. J Rural Health 2008;24:183-8. 